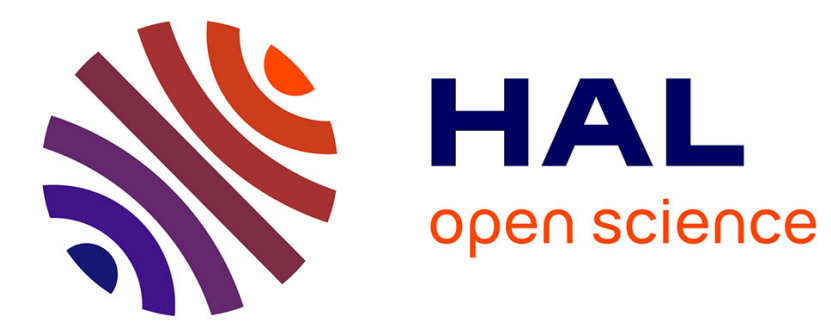

\title{
Role of eicosanoids on intestinal epithelial homeostasis
}

\author{
Rut Ferrer, Juan J. Moreno
}

\section{To cite this version:}

Rut Ferrer, Juan J. Moreno. Role of eicosanoids on intestinal epithelial homeostasis. Biochemical Pharmacology, 2010, 80 (4), pp.431. 10.1016/j.bcp.2010.04.033 . hal-00601184

\section{HAL Id: hal-00601184 https://hal.science/hal-00601184}

Submitted on 17 Jun 2011

HAL is a multi-disciplinary open access archive for the deposit and dissemination of scientific research documents, whether they are published or not. The documents may come from teaching and research institutions in France or abroad, or from public or private research centers.
L'archive ouverte pluridisciplinaire HAL, est destinée au dépôt et à la diffusion de documents scientifiques de niveau recherche, publiés ou non, émanant des établissements d'enseignement et de recherche français ou étrangers, des laboratoires publics ou privés. 


\section{Accepted Manuscript}

Title: Role of eicosanoids on intestinal epithelial homeostasis

Authors: Rut Ferrer, Juan J. Moreno

PII:

S0006-2952(10)00334-5

DOI: doi:10.1016/j.bcp.2010.04.033

Reference: $\quad$ BCP 10550

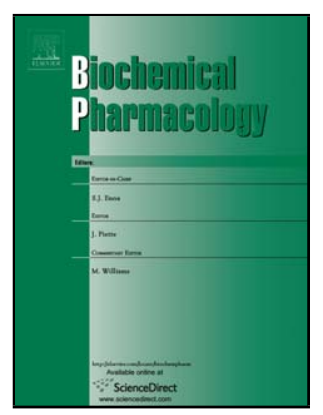

To appear in: $\quad B C P$

Received date: $\quad 3-3-2010$

Revised date: $\quad 28-4-2010$

Accepted date: $\quad$ 29-4-2010

Please cite this article as: Ferrer R, Role of eicosanoids on intestinal epithelial homeostasis, Biochemical Pharmacology (2008), doi:10.1016/j.bcp.2010.04.033

This is a PDF file of an unedited manuscript that has been accepted for publication. As a service to our customers we are providing this early version of the manuscript. The manuscript will undergo copyediting, typesetting, and review of the resulting proof before it is published in its final form. Please note that during the production process errors may be discovered which could affect the content, and all legal disclaimers that apply to the journal pertain. 
Role of eicosanoids on intestinal epithelial homeostasis

Rut Ferrer and Juan J. Moreno*

Department of Physiology, Faculty of Pharmacy, University of Barcelona, Avda Joan XXIII s/n, 08028 Barcelona, Spain

* Corresponding author. Tel.: 3493 4024505; fax: 34934035901

E-mail addresses: $\underline{\text { rutferrer@ub.edu }}$ (R. Ferrer), jjmoreno@ub.edu (J.J. Moreno)

\begin{abstract}
Abbreviations: AA, arachidonic acid; COX, cyclooxygenase; EETs, epoxyeicosatrienoic acids; EGF, epidermal growth factor; HETEs, hydroxyeicosatetraenoic acids; HODE, hydroxyoctadecadienoic acids; IBD, inflammatory bowel disease; LOX, lipoxygenase; LTs, leukotrienes; PSC, prostaglandin-expressing stromal cells; PGs, prostaglandins; $\mathrm{cPLA}_{2}$, cytosolic phospholipase $\mathrm{A}_{2} ;$ iPLA $_{2}$, calcium-independent phospholipase $\mathrm{A}_{2} ; \mathrm{sPLA}_{2}$, secreted phospholipase $\mathrm{A}_{2}$; PPAR, peroxisome proliferator-activated receptor; NSAIDs, nonsteroidal anti-inflammatory drugs; TJ, tight junction; ZO, zonula occludens
\end{abstract}


The intestinal epithelium is a highly dynamic system that is continuously renewed by a process involving cell proliferation and differentiation. Moreover, it is the main interface with the external environment, and maintenance and regulation of the epithelial structure and epithelial barrier function are key determinants of digestive health and host well-being. The tight junction, a multiprotein complex composed of transmembrane proteins associated with the cytoskeletal peri-junctional ring of actin and myosin, is an essential component of this barrier that is strictly regulated in a spatio-temporal manner by a complex signaling network. Defects in the intestinal epithelial barrier function have been observed in inflammatory bowel disease, and a classic example of the connection between inflammation and cancer is the increased risk of colorectal cancer in patients with inflammatory bowel disease. In recent years, several molecules have emerged as critical players contributing to inflammationassociated colorectal cancer. For example, eicosanoids derived from arachidonic acid are proposed as mediators involved in the regulation of epithelial structure/function. Interestingly, the tissue concentration of eicosanoids increases during mucosal inflammation and colorectal cancer development. This overview focuses on the physiological and physiopathological roles of eicosanoids in cell growth/cell differentiation/apoptosis and in the paracellular permeability of the intestinal epithelium. A better understanding of these processes will foster new ideas for the development of therapies for these chronic disorders.

Keywords: prostaglandin, leukotriene, hydroxyeicosatetraenoic acid, cell proliferation, cell differentiation, barrier function 


\section{Introduction. The intestinal epithelium}

The whole digestive tract is fenced by an epithelial monolayer composed of different cell types. The surface area of the small intestine is increased by luminal protrusions, termed villi, and invaginations into the mucosa, the crypts of Lieberkühn. In the mucosa of the large intestine there are no villi, only crypts. Three differentiated cell types (enterocytes, enteroendocrine, and goblet cells) populate the villi, whereas Paneth cells reside at the bottom of the crypts together with stem cells that can be considered the crypt/villus progenitors. Stem cells divide every $12-16 \mathrm{~h}$, generating 200 cells per crypt every day. This cell production is compensated by cell shedding at the tip of the villi (small intestine) or at the surface of the epithelium (large intestine). This proliferative process pushes cells to the top of the villus. Thus, the top of the crypts and villi contains terminally differentiated cells, whereas Paneth cells and stem cells escape this movement and consequently remain permanently at the bottom of the crypts [1]. The proliferative state of stem cells must therefore be regulated by extrinsic cues that report the tissue status and thus adjust the rate of tissue renewal. The nature of these signals, how they are regulated, and how they activate stem cells are mostly unknown. However, given their importance for understanding epithelium homeostasis, epithelium repair processes and colorectal cancer, it would be interesting to shed light on these issues.

The intestinal epithelium is thus a highly dynamic system that is continuously renewed by a process involving cell proliferation and differentiation. Moreover, it is the main interface with the external environment, and maintenance and regulation of the epithelial structure and epithelial barrier function are key determinants of digestive health and host well-being. For the maintenance of gut homeostasis it is imperative that the permeability characteristics of the epithelium are tightly regulated so that the seemingly paradoxical functions of allowing nutrient uptake, while excluding 
potentially harmful antigens from entering the mucosa, can coexist. In situations in which enhanced or prolonged leakiness of the epithelial barrier occurs, the result can be the passage of excessive amounts of pathogenic bacteria and toxic luminal antigens including endotoxins [2] into the mucosa, eliciting an immune response that, if not properly controlled, can lead to chronic inflammation [3].

The mechanisms that regulate the intestinal paracellular permeability to luminal substances and preserve its functional integrity are not completely understood. However, crucial for this integrity are cell polarity and the multifaceted dynamic interactions between the cell adhesion complexes and tight junctions (TJ) with the actin cytoskeleton [4]. Thus, paracellular permeability is regulated primarily by the most apical epithelial intercellular junction, the TJ or zonula occludens (ZO). An intact intestinal epithelial TJ barrier is crucial for providing a barrier function. TJ is a complex multiprotein that is composed of both intracellular and membrane-spanning proteins. Four distinct types of membrane protein have been localized to TJ: occludin, claudins, junctional adhesion molecules and the coxsackie virus and adenovirus receptor, whereas the intracellular complex of TJ-associated proteins includes ZO-1, ZO-2, ZO-3, cingulin, 7H6, symplekin, and ZA-1 [5].

The present commentary will focus on the role of arachidonic acid (AA) cascade enzymes as well as mediators derived from this cascade on intestinal epithelial cell proliferation/differentiation, intestinal barrier function, and immune cells that are present in the epithelium, and consequently on intestinal epithelial homeostasis. 


\section{Eicosanoids and the intestine}

AA is an important polyunsaturated fatty acid of cell membrane phospholipids and also a cellular mediator that acts by itself or following its transformation to eicosanoids, its oxidized biologically active products. Under physiological conditions, the amount of free intracellular available AA is quite low. However, AA release from phospholipids occurs through the activation of phospholipases, primarily phospholipase $\mathrm{A}_{2}$ (PLA $\mathrm{PL}_{2}$.

$\mathrm{PLA}_{2}$ comprises a large superfamily of distinct enzymes that exhibit different substrate specificities, cofactor requirements, and subcellular localizations, and includes secreted $\mathrm{PLA}_{2} \mathrm{~S}\left(\mathrm{sPLA}_{2} \mathrm{~S}\right)$, cytosolic $\mathrm{PLA}_{2} \mathrm{~S}\left(\mathrm{cPLA}_{2} \mathrm{~s}\right)$ and calcium-independent $\mathrm{PLA}_{2} \mathrm{~S}$ $\left(\mathrm{iPLA}_{2} \mathrm{~s}\right)$. Upon release from biomembranes, AA can be metabolized via three enzymatic pathways: the cyclooxygenase (COX), lipoxygenase (LOX) and cytochrome P-450 pathways. The COX pathway leads to the formation of thromboxanes and prostaglandins (PGs). There are two COX isozymes: COX-1, which is expressed constitutively and COX-2, an inducible enzyme that is expressed in the majority of mammalian cells. Both isozymes catalyze the synthesis of $\mathrm{PGH}_{2}$ from AA which is metabolized by specific prostaglandin synthases to release PGs. LOXs insert a hydroxyperoxyl group into the AA, which is subsequently reduced to produce hydroxyeicosatetraenoic acids (HETEs). Thus, 5-LOX leads to the synthesis of 5HETE, whereas 12- and 15-LOX can form 12- and 15-HETE. 5-HETE can be metabolized to synthesize leukotrienes (LTs) such as $\mathrm{LTB}_{4}$ and the cysteinyl LTs $\left(\mathrm{LTC}_{4}, \mathrm{LTD}_{4}\right.$ and $\left.\mathrm{LTE}_{4}\right)$. Finally, the cytochrome P-450 monooxygenases also metabolize AA by allylic oxidation, $\omega / \omega-1$ hydroxylation or epoxydation to synthesize a wide range of eicosanoids such as HETEs (20-HETE) and epoxyeicosatrienoic acids (EETs) [6,7] (Fig. 1). 
Eicosanoids have pleitropic effects on cell physiology and signal transduction and exerts their actions through binding to specific members of the $\mathrm{G}$ protein-coupled seven transmembrane domain receptor family. The main prostanoid receptors are the DP $\left(\mathrm{DP}_{1}-\mathrm{DP}_{2}\right)$ receptors to $\mathrm{PGD}_{2}, \mathrm{EP}\left(\mathrm{EP}_{1}-\mathrm{EP}_{4}\right)$ receptors to $\mathrm{PGE}_{2}, \mathrm{FP}$ receptor to $\mathrm{PGF}_{2 \alpha}$, IP receptor to $\mathrm{PGI}_{2}$ and $\mathrm{TP}$ receptor to thromboxanes. Two $\mathrm{LTB}_{4}$ receptors have been characterized: $\mathrm{BLT}_{1}$ is a high-affinity receptor whereas $\mathrm{BLT}_{2}$ is a low-affinity receptor; cysteinyl LTs activate at least two receptors referred to as the CysLT 1 and $\mathrm{CysLT}_{2}$ receptors (Fig. 1). Although HETEs and EETs were first described several decades ago, relatively little is known about their mechanism of action. The fact that HETE and EET receptors have not been identified may have contributed to this. Finally, we must consider that peroxisome proliferator-activated receptors that are expressed in the intestinal mucosa and involved in the regulation of cell growth/differentiation and intestinal inflammation can be activated by eicosanoids $[8,9]$.

Regarding the characterization of eicosanoid production within the intestinal tract, considerable variability exists among different species as well as different anatomic locations. Thus, important regional variations in eicosanoid profiles exist throughout the gut [10]. The cells most likely to be responsible for eicosanoid production include immune cells in the lamina propria and subepithelial mesenchymal cells [10]; however, intestinal epithelial cells have also been shown to be capable of eicosanoid production [10]. In cultured intestinal epithelial cells, prostanoid production has been shown to increase after treatment with growth factors and phorbol esters [11]. In contrast to their production, PG degradation seems to occur in the epithelial layer rather than in the subepithelium [10]. This could contribute to establish a PGs gradient along the cryp/villus axis, although this has yet to be demonstrated (Fig. 2). 
Shoji et al. [12] reported that four $\mathrm{PGE}_{2}$ receptor $\left(\mathrm{EP}_{1}-\mathrm{EP}_{4}\right)$ mRNAs were expressed in human colon tissues. Moreover, they observed $\mathrm{EP}_{1}, \mathrm{EP}_{2}$ and $\mathrm{EP}_{4} \mathrm{mRNA}$ expression in intestinal epithelial cells. Interestingly, a different regional distribution of PG receptors was reported in intestinal mucosa.

Transformed and non-transformed intestinal epithelial cell lines [13-15] as well as the human intestine $[16,17]$ also produce LOX metabolites such as LTs and HETEs, whereas there is no information about HETE/EET production by cytochrome P-450 in intestinal epithelial cells or the intestine. With respect to the presence of LT receptors in the intestine, the $\mathrm{CysLT}_{1}$ receptor is expressed in intestinal epithelial cells and tumorderived intestinal cells [15] whereas the CysLT $_{2}$ receptor is expressed in differentiated intestinal epithelial cells but not in tumor-derived intestinal cell lines [18]. The BLT 1 receptor is also expressed in human colon cancer cell lines and colon cancer tissue but not in normal colon tissue [19].

\section{Role of eicosanoids in the control of intestinal epithelial cell growth}

Our previous findings demonstrating that AA release by iPLA 2 participates in the signaling pathways involved in the control of intestinal epithelial proliferation [20] showed that $\mathrm{PLA}_{2}$ and COX-2 are involved in $\mathrm{PGE}_{2}$ release in proliferative epithelial cells, whereas differentiation appears to depress this pathway. These events could also be necessary for the completion of epithelial cell differentiation, or at least for the development of the epithelial barrier function that is characteristic of differentiated epithelium [21]. Defining the molecular mechanisms of action of PGs on cell growth is an area of intense research. Epidermal growth factor (EGF) appears to be a key constituent in the maintenance, growth, repair and barrier integrity of the gastrointestinal mucosa. Recent studies have demonstrated the transactivation of the 
EGF receptor by $\mathrm{PGE}_{2}$ in intestinal epithelial cells [22]. Moreover, the Wnt signaling cascade and the activation of PPAR $\delta$ are involved in the effects of PGs on the proliferation of non-transformed and transformed intestinal epithelial cells.

Furthermore, $\mathrm{PGE}_{2}$ could be involved in the control of the intestinal epithelial cell cycle machinery through the up-regulation of cyclin $\mathrm{B}_{1}$ and down-regulation of $\mathrm{p} 21$ expression independently of p53 [23]. Thus, this proliferative effect of $\mathrm{PGE}_{2}$ contributes to the development of the epithelium and could be involved in the intestinal epithelial response to injury (Fig. 2). These events could be related to the observation that shortterm administration of $\mathrm{PGE}_{2}$ causes significant stimulation of DNA synthesis and that prolonged $\mathrm{PGE}_{2}$ treatment markedly increases the weight and DNA content of the intestinal mucosa [24].

Interactions between intestinal epithelial cells and stromal cells, which include fibroblasts, myofibroblasts, endothelial cells and other cell types, may dramatically influence the growth and transformation of the intestinal epithelium [25]. PGs and other eicosanoids are synthesized by these cells [26,27]. Eicosanoids derived from both stromal and epithelial cells may stimulate stromal cells to release growth factors, which, in turn, provide a pro-proliferative and pro-neoplastic environment for the intestinal epithelium. Shao et al. [28] found that exogenous $\mathrm{PGE}_{2}$ induced the expression and secretion of several pro-proliferative and pro-angiogenic growth factors such as amphiregulin, vascular endothelial growth factors, hepatocyte growth factor and neuregulins by intestinal subepithelial myofibroblasts, which may mediate intestinal epithelial growth and transformation. Finally, we must consider that activated macrophages also produce eicosanoids [29] that are present near the epithelial progenitor niche [30]. All these cells, in addition to eicosanoids and growth factors 
produced are strategically located leading an instructive communication with the epithelial stem cells and their descendants.

In agreement with the above mentioned papers, Stenson [31] addressed these effects of PGs, particularly $\mathrm{PGE}_{2}$, in the intestinal epithelial response to injury in a radiation injury model and in colitis models. Brown et al. [32] reported that epithelial tissue contains cells that express COX-2 at high levels, named prostaglandin-expressing stromal cells (PSCs) (Fig. 2). They observed that the majority of PSCs were located in the lamina propria lining the upper and middle third of the rectal crypt. However, after injury, the number of PSCs at the crypt bottom, adjacent to the intestinal stem cells compartment, increased, and consequently the $\mathrm{PGE}_{2}$ levels. These authors proposed that local production of $\mathrm{PGE}_{2}$ by PSCs may be involved in regulating epithelial proliferation after injury. However, other authors proposed that the $\mathrm{PGE}_{2}$ involved in epithelial tissue repair is due to COX-1 rather than COX-2 [33]. In this way, radiation injury results in increased COX-1 levels in crypt stem cells and their progeny, and that $\mathrm{PGE}_{2}$ produced through COX-1 promotes crypt stem cell survival and proliferation [34]. Although it is increasingly accepted that the COX pathway is involved in physiological and pathophysiological cell growth, the role of COX isoforms is still a matter of debate.

The human colon is also able to produce lipoxygenase metabolites [16] and these AA-derived metabolites have also been implicated in the control of intestinal epithelial cell growth. Thus, endogenous production of $\mathrm{LTD}_{4}$ mediates autocrine survival and proliferation via the nuclear- and membrane-located $\mathrm{CysLT}_{1}$ receptor, triggering a proliferative ERK1/2 signal in non-transformed and transformed intestinal epithelial cells $[15,35]$.

There is little information about HETE/EET production by intestinal epithelial cells or the effect of these eicosanoids on intestinal epithelial growth, although many recent 
papers have focused on the emerging effects of HETEs on cell signaling and physiological/pathological cell growth [36]. Given that 5-LOX [14], 12-LOX [13] and 15-LOX [37] are expressed by intestinal epithelial cells and that there is differentiated expression of these enzymes during epithelial cell differentiation, these eicosanoids may also have an important role in the physiology of the epithelium. Thus, Kamitani et al. [13] suggested that 12-LOX, and/or the lipid products synthesized by this enzyme are involved in intestinal epithelial cell differentiation and apoptosis. Recently, Collins et al. [17] reported that 12-LOX was increased by up to > 100-fold throughout the entire length of the intestine of iron-deficient animals, inducing a strong increase in 12-HETE and 13-hydroxyoctadecadienoic acid (13-HODE) intestinal levels that was correlated with an increase in the number of mitotic cells. Interestingly, these changes in the 12LOX pathway induce a series of structural changes in the intestine such as increased villus height, width and crypt depth. This elegant experimental model leads to related changes in the expression of AA cascade enzymes and subsequent eicosanoid production, with epithelial cell growth and significant morphological changes in the intestinal mucosa.

Colon cancer is the third most common cancer and the second leading cause of cancer-related deaths. The incidence of colon cancer doubles with each decade of life after the age of fifty. Although a great deal of effort has been made toward developing screening strategies, aggressive surgical therapy, and other therapies, there has been little improvement in the outcome for patients with advanced disease.

Today, the causal relationship between inflammation, innate immunity and cancer is more widely accepted; nevertheless, many of the molecular and cellular mechanisms mediating this relationship remain unresolved. However, there is now evidence that inflammatory mediators have a powerful effect on tumor development. Early in the 
neoplastic process, eicosanoids could be powerful tumor promoters, producing an attractive environment for tumor growth and promoting angiogenesis. Thus, studies in the early 1980s indicated that non-steroidal anti-inflammatory drugs (NSAIDs) were chemopreventive in animal models of colon cancer [38]. In 1991, Thun et al. [39] reported that aspirin use reduce the relative risk of colon cancer and colon cancer mortality among 600,000 individuals, whereas acetaminophen, which does not affect COX activity, did not provide as protective an effect. Even more relevant for the clinician were subsequent studies that demonstrated that NSAID therapy can cause the regression of adenoma in patients with familial adenomatous polyposis [40]. Furthermore, COX-2 is elevated in colorectal cancers [41], with 50\% of adenomas and 80-90\% of adenocarcinomas exhibiting increased COX-2 expression, and elevated $\mathrm{PGE}_{2}$ and 6-keto $\mathrm{PGF}_{1 \alpha}$ levels $[42,43]$. However, conflicting data exist regarding the localization of COX-2 in the epithelium or stromal components of colorectal tumors. Using an elegant experimental model, Oshima et al. [44] reported that COX-2 is located in the stromal component and may promote tumor growth by producing bioactive PGs that affect tumor growth in a paracrine fashion. This is consistent with the model postulated by Kinzler and Vogelstein [45], which states that COX-2 affects tumor growth by acting as a landscaping tumor promoter in the stromal component of the adenoma.

Despite the very strong evidence of a causative role of prostaglandins in general, and $\mathrm{PGE}_{2}$ in particular, in intestinal cancer, the underlying molecular mechanisms have remained obscure until recently. However, studies by several research groups are now clarifying this point. Dietary manipulation of AA content in $\mathrm{APC}^{\text {min }}$ animals suggests that $\mathrm{AA}$ is involved in tumorigenesis [46]. Using $\mathrm{APC}^{\text {min }}$ induced tumorigenesis and $\mathrm{CPLA}_{2}^{-{ }^{-l}}$ mice, Hong et al. [47] demonstrated the pivotal role of enzymes involved in 
AA release in small intestine polyp formation whereas they observed a trend in the opposite direction in the small intestine, probably, by limiting proapoptotic signals [48]. Furthermore, a number of animal studies involving APC-mutant mice are converging on a central pathway involving the COX pathway. In addition, a recent study by Castellone et al. [49] demonstrated that $\mathrm{PGE}_{2}$ increases the activation of the Tcf/Lef transcription factor and activated components of the canonical Wnt signaling cascade. Thus, $\mathrm{PGE}_{2}$ EP receptor interaction results in the displacement of APC and the loss of phosphorylation of $\beta$-catenin. In the absence of phosphorylation, $\beta$-catenin is not degraded, but instead translocates to the nucleus and activates Tcf/Lef. A possible alternative mechanism by which PGs may induce cell growth is the EGF pathway. EGF receptor (EGFR) signaling is more relevant to early APC-dependent tumorigenesis, and $\mathrm{PGE}_{2}$ can transactivate EGFR in intestinal epithelial cells and consequently the EGFRPI3K-Akt cell survival/proliferative pathway in vivo, as reported recently by Moran et al. [43]. These findings support the original hypothesis that the anti-tumorigenesis effects of NSAIDs work through decreased PG production. However, these explanations have lacked molecular detail, in large part because of a poor understanding of which PG receptors are involved. In the last decade, important findings were obtained with respect to this point. Targeted deletion of the $\mathrm{EP}_{1}$ receptor reduced colonic lesions by $60 \%$ in a colon cancer experimental model and $\mathrm{APC}^{\mathrm{min}}$-induced polyp formation was also reduced by $57 \%$ following treatment with a specific $\mathrm{EP}_{1}$ antagonist [50]. Considering all together, we now have a complete picture of the main elements involved in the effects of PGs such as $\mathrm{PGE}_{2}$ on epithelial cell growth in physiological and pathophysiological conditions: AA is released by $\mathrm{PLA}_{2}$, then metabolized by COX-1/COX-2 to produce bioactive eicosanoids such as $\mathrm{PGE}_{2}$, which 
interact with specific receptors $\left(\mathrm{EP}_{1}\right.$ and $\left.\mathrm{EP}_{4}\right)$ and activate the cell signaling involved in the control of the cell cycle.

Research on PPARs has revealed that they play a fundamental role in cellular proliferation/differentiation processes [51]. In human colon cancer cell lines and tumor cells, $\mathrm{PGE}_{2}$ transactivates PPAR $\delta$ through the PI3 kinase/Akt pathway. $\mathrm{PGE}_{2}$ treatment of $\mathrm{APC}^{\mathrm{min}}$ mice increased the intestinal adenoma burden; however, $\mathrm{PGE}_{2}$ had no effect on the adenoma burden in $\mathrm{APC}^{\mathrm{min}}$ mice deficient in PPAR $\delta$. Other findings indicate that the proliferative effects of $\mathrm{PGE}_{2}$ are also mediated through PPAR $\delta$ [52].

Cianchi et al. [53] reported that the two major metabolic pathways of the AA cascade, COX and 5-LOX, are simultaneously up-regulated in human colorectal cancer. Interestingly, inhibition of either COX or 5-LOX alone resulted in activation of the other pathway, and consequently, combined treatment with COX and 5-LOX modulators produced greater inhibition of tumor cell proliferation. High expression of the $\mathrm{BLT}_{1}$ receptor [19] and the CystLT $\mathrm{T}_{1}$ receptor was detected in human colon cancer tissues, whereas $\mathrm{CysLT}_{2}$ receptor expression was reduced in colon cancer and was associated with poor prognosis, due to its capacity to induce differentiation and growth inhibition [18]. Thus, the $\mathrm{CysLT}_{2}$ receptor could have more anti-tumorigenic activity than the $\mathrm{CysLT}_{1}$ receptor in intestinal epithelial cells, and the balance between the two receptors is important for the outcome of tumor progression. These findings indicate that AA cascade enzyme expression and eicosanoid production are important, but that the balance between eicosanoid receptors is also important for tumor progression and disease outcome.

Dietary fiber (non-starch polysaccharides) bypasses digestion in the stomach and small intestine, as do oligosaccharides and some resistant starches. In the large intestine, symbiotic bacteria ferment these carbohydrates releasing butyrate, a short chain fatty 
acid, as a by-product. At physiological concentrations, butyrate has been shown to induce growth inhibition, differentiation and apoptosis in colorectal tumor cells in vitro [54]. These observations may explain, in part, the correlation between a high fiber diet and a low incidence of colorectal cancer. Crew et al. [55] observed that COX-2 inhibitors sensitize the cell to growth inhibition induced by butyrate in colorectal carcinoma cells expressing COX-2 protein. These findings may mean that high fiber diet content would enable lower doses of COX-2 inhibitors to be used in chemoprevention.

Despite progress in knowledge of the effect of PGs and LTs on intestinal epithelial cell growth, we are a long way from fully understanding the role of the AA cascade in intestinal epithelial cell growth/differentiation/apoptosis, which will hopefully lead to a greater understanding of colorectal cancer in terms of the molecular pathways involved, and thus provide potential applications for the clinical setting.

\section{Role of eicosanoids in the control of intestinal barrier function}

Inflammatory bowel disease (IBD) including Crohn's disease and ulcerative colitis, is characterized by chronic, relapsing inflammation of the gastrointestinal tract, affecting at least 1 in 1000 people in Western countries [56]. Although the molecular mechanisms underlying the pathogenesis of IBD have not been identified, at least two events in which eicosanoids are involved have been described. The first is defects in the mucosal barrier, which may allow the continuous stimulation of the mucosal immune system due to impairment of the epithelial barrier function. Increased paracellular permeability of the epithelium has been well documented both in acutely and chronically damaged areas of the intestine [57]. Moreover, it is well known that intestinal permeability is regulated directly through alteration of TJ proteins, or 
indirectly through effects on the cytoskeleton. However, although altered intestinal permeability has been reported in patients with IBD, and the grade of barrier defect related to the onset of symptoms, the mechanism responsible and the mediators have not been completely identified. In fact, TNF- $\alpha$ and IFN- $\gamma$ have been identified as being responsible, at least in part, for the increase in paracellular permeability [58,59], and the mechanisms underlying the regulation of TJ permeability by TNF- $\alpha$ and IFN- $\gamma$ either directly through the alteration of TJ proteins, or indirectly through effects on the cytoskeleton have been well documented [60].

The second event that occurs in IBD is an increase in the inflammatory response with an associated increase in cytokine, eicosanoid and free radical production. Eicosanoids play a significant role in IBD as mediator of inflammation. Thus, the levels of prostanoids such as $\mathrm{PGE}_{2}, \mathrm{PGF}_{2 \alpha}$ and $\mathrm{PGD}_{2}$, as well as 12-HETE, 15-HETE and $\mathrm{LTB}_{4}$ are higher in inflamed compared to normal mucosa $[61,62]$. Moreover, the increase in $\mathrm{PGE}_{2}$ levels is correlated with disease activity [63]. Furthermore, during remission, $\mathrm{PGE}_{2}$ and $\mathrm{LTB}_{4}$ levels return to values comparable with normal colorectal mucosa [61]. The enhancement of PGs is a consequence of the overexpression of COX and prostaglandin synthases in inflamed intestinal mucosa [64]. This supports the role of eicosanoids in IBD. Further evidence that supports the importance of eicosanoids in IBD is that sulfasalazine, mesalamine and glucocorticoids, effective treatments, reduce eicosanoid synthesis $[65,66]$.

Enteroinvasive bacteria that are responsible for diarrheal diseases also activate the expression of genes such as COX-2 in the intestinal epithelium, provoking $\mathrm{PGE}_{2}$ production and consequently impaired barrier function [67]. On the other hand, we must consider that intestinal epithelial cells have the capacity to recognize and respond to commensal microbiota. Elements of the microbiota inhibit the NF-kB pathway by 
hijacking the PPAR- $\gamma$ pathway, and consequently modulate the COX pathway [68].

Activation of PPAR- $\gamma$ by butyrate has also been shown to reduce colonic permeability, probably through the promotion of intestinal epithelial cell differentiation and the consequent reinforcement of the TJs [69]. The microflora seems to be regulated to ensure protection from injury and induction of repair. An attractive hypothesis is that under normal physiological conditions the coordinated induction of various protective mechanisms helps to control pivotal elements involved in the AA cascade, thus maintaining normal epithelial cell homeostasis and the interplay with commensal bacteria.

In summary it seems that $\mathrm{AA}$ release and $\mathrm{PGE}_{2}$ synthesis by the $\mathrm{COX}$ pathway could be involved in the regulation of intestinal paracellular permeability (Fig. 2). Thus, we observed that intestinal epithelial differentiation induces a decrease in both $\mathrm{PLA}_{2}$ activity and COX-2 expression and, consequently, a decrease in AA release and $\mathrm{PGE}_{2}$ synthesis in parallel with a reduction in paracellular permeability and consequently the development of a barrier function that can be disrupted by the exogenous addition of $\mathrm{PGE}_{2}$ [21]. Recently, we observed that this modulation of the epithelial barrier function is mediated by the interaction with $\mathrm{PGE}_{2}$ receptors $\mathrm{EP}_{1}$ and $\mathrm{EP}_{4}$. Events that activate PLC-IP ${ }_{3}-\mathrm{Ca}^{2+}$ and cAMP-PKA pathways that lead to an intracellular calcium concentration and the redistribution of $\mathrm{TJ}$ proteins such as occludin and the perijunctional actin ring that may be mediated these effects [70].

Given that NSAIDs, which are COX pathway inhibitors, might exacerbate the extent of IBD as well as epithelial barrier disruption [71], we must consider whether other eicosanoids have any effect on the elements that regulate epithelial barrier function. There is no information about the evolution of LOX expression in IBD, an important step in the AA cascade in this pathophysiological condition. Moreover, to the date, there 
is little information on the effects of eicosanoids produced by this pathway on TJ and consequently on barrier function. However, Rodríguez-Lagunas et al. [72] have recently reported that $\mathrm{LTD}_{4}$ and 5-, 12- and 15-HETE produced by the LOX pathway alter the epithelial barrier function to a greater extent than prostanoids. Thus, the administration of NSAIDs could allow LT and HETE synthesis by the LOX pathway to proceed unchecked while blocking PG formation, and hypothetically could shift the net effect of prevailing eicosanoids toward proinflammation and the impairment of barrier function (Fig. 3). These findings might explain the negative effects of NSAID treatments on IBD evolution.

\section{Eicosanoids as immunoregulatory factors in intestinal mucosa}

Another important aspect of the actions of eicosanoids in the intestine is their immunoregulatory effect. The close proximity of a wide array of antigens and lymphocytes in the gastrointestinal tract emphasizes the need to maintain immunological homeostasis and avoid an inappropriate immune response to nonpathogenic antigens, with subsequent epithelial alterations. Eicosanoids may also be involved in this process. $\mathrm{PGE}_{2}$ is known to have immunomodulatory effects: it downregulates the major histocompatibility complex class II and cytokine receptor expression as well as cytokine production [73,74], events that might be involved in controlling an inflammatory immune response to dietary antigens. Consequently, PGs produced by epithelial cells, fibroblasts or lamina propria mononuclear cells could downregulate the intestinal immune system (Fig. 3). The importance of COX-dependent AA metabolites as immunoregulatory factors in the intestinal mucosa is supported by the observation that NSAIDs exacerbate clinical activity in human inflammatory bowel disease [71]. In addition, some COX $-2^{-/-}$mice show peritonitis and intestinal abscess 
formation, possibly secondary to inappropriate immune activation in the absence of high levels of $\mathrm{PGE}_{2}$ [75]. Newberry et al. [76] proposed that $1 \mathrm{nM} \mathrm{PGE} 2$ could have this immunomodulatory effect, such a concentration being reached in the intestinal mucosa. It will be necessary to study the effects of other eicosanoids such as HETEs and EETs on intestinal immunoregulation to clarify their role in this important aspect of intestinal epithelial homeostasis.

\section{Conclusions and perspectives}

An attractive hypothesis is that under normal physiological conditions the coordinated induction of various protective mechanisms helps to control pivotal elements involved in the AA cascade, but the increase in eicosanoid mucosal levels may contribute to the development of inflammatory processes as well as colorectal cancer. Answers to the question considered during this commentary may help us to determine the role of eicosanoids in the maintenance of intestinal homeostasis as well as to design protocols for using dietary modifications or pharmacological treatments in the prevention or treatment of IBD and colorectal cancer.

Given the different effects of eicosanoids we must consider that pharmacological manipulation of the AA cascade may have contradictory effects. For example, NSAID treatments reduce the risk of colorectal cancer whereas they exacerbate IBD. In the same way, treatment with an $\mathrm{EP}_{4}$ receptor antagonist protected against the development of colon cancer [77], but exacerbated experimental colitis [78]. The rational design of treatments that allow the impairment of cell growth or barrier dysfunction induced by eicosanoids without upregulation of the immune response may be a useful approach for IBD and colorectal cancer. 
In conclusion, more studies are needed to clarify the pivotal questions that remain unanswered in this exciting field. In particular, additional work is required to explore mechanistic issues involving the effects of LTs and HETEs/EETs on epithelial cell growth/differentiation, barrier function, and on the intestinal immune response. 


\section{Acknowledgements}

The authors gratefully acknowledge the support of the Generalitat de Catalonia (2005SGR00269 and 2009SGR00438) and the financial support of the Ministry of Sciences and Technology (BFI2004-0496/BFI and BFI2007-61727/BFI) for grant funding. 


\section{References}

[1] Sancho E, Batlle E, Clevers H. Signalling pathways in intestinal development and cancer. Ann Rev Cell Dev Biol 2004;20:695-723.

[2] Anderson JM, VanItallie CM. Tight junctions and the molecular basis of regulation of paracellular permeability. Am J Physiol Gastrointestinal and Liver Physiol 1995; 269:G467-G475.

[3] Bruewer M, Samarin S, Nusrat A. Inflammatory bowel disease and the apical junctional complex. Ann N Y Acad Sci 2006;1072:242-252.

[4] Hartsock A, Nelson WJ. Adherens and tight junctions: structure, function and connections to the actin cytoskeleton. Biochim Biophys Acta 2008;1778:660-669.

[5] Furuse M, Fujita K, Hiiragi T, Fujimoto K, Tsukita S. Claudin-1 and -2: novel integral membrane proteins localizing at tight junctions with no sequence similarly to occluding. J Cell Biol 1998;141:1539-1550.

[6] Goetzl EJ, Smith WL. Specificity of expression and effects of eicosanoid mediators in normal physiology and human diseases. FASEB J 1995;9:1051-1058.

[7] Capdevila JH, Falck JR, Harris RC. Cytochrome P-450 and arachidonic acid bioactivation. Molecular and functional properties of the arachidonate monooxygenase. J Lipid Res 2000;41:163-181.

[8] Na HK, Surh YJ. Peroxisome proliferator-activated receptor gamma (PPAR gamma) ligands as bifunctional regulators of cell proliferation. Biochem Pharmacol 2003;66:1381-1391.

[9] Rizzo G, Fiorucci S. PPARs and other nuclear receptors in inflammation. Curr Opinion Pharmacol 2006;6:421-427. 
[10] Smith GS, Warhurst G, Turnberg LA. Synthesis of degradation of prostaglandin $E_{2}$ in the epithelial and sub-epithelial layers of the rat intestine. Biochim Biophys Acta 1982;713:684-687.

[11] Dubois RN, Awad J, Morrow J, Roberts LJ, Bishop PR. Regulation of eicosanoid production and mitogenesis in rat intestinal epithelial cells by transforming growth factor-alpha and phorbol ester. J Clin Invest 1994;93:493-498.

[12] Shoji Y, Takahashi M, Kitamura T, Watanabe K, Kawamori T, Maruyama T, et al. Downregulation of prostaglandin $\mathrm{E}$ receptor subtype $\mathrm{EP}_{3}$ during colon cancer development. Gut 2004;53:1151-1158.

[13] Kamitani H, Ikawa H, His LC, Watanabe T, Dubois RN, Eling TE. Regulation of 12-lipoxygenase in rat intestinal epithelial cell during differentiation and apoptosis induced by sodium butyrate. Arch Biochem Biophys 1999;368:45-55.

[14] Wächtershäuser A, Steinhilber D, Loitsch SM, Stein J. Expression of 5lipoxygenase by human colorectal carcinoma Caco-2 cells during butyrate-induced cell differentiation. Biochem Biophys Res Commun 2000;268:778-783.

[15] Paruchuri S, Mezhybovska M, Juhas M, Sjölander A. Endogenous production of leukotriene $\mathrm{D}_{4}$ mediates autocrine survival and proliferation via CysLT1 receptor signalling in intestinal epithelial cells. Oncogene 2006;25:6660-6665.

[16] Dreyling KW, Hoppe U, Peskar BA, Morgenroth K, Kozuschek W, Peskar BM. Leukotriene synthesis by human gastrointestinal tissues. Biochim Biophys Acta 1986;878:184-193.

[17] Collins JF, Hu Z, Ranganathan PN, Feng D, Garrick LM, Garrick MD, Browne RW. Induction of arachidonate 12-lipoxygenase (Alox 15) in intestine of iron-deficient rats correlates with the production of biologically active lipid mediators. Am J Physiol Gastrointetinal and Liver Physiol 2008;294:G948-G962. 
[18] Magnusson C, Ehrnström R, Olsen J, Sjölander A. An increased expression of cysteinyl leukotriene 2 receptor in colorectal adenocarcinomas correlates with high differentiation. Cancer Res 2007;67:9190-9198.

[19] Ihara A, Wada K, Yoneda M, Fujisawa N, Takahashi H, Nakajima A. Blockade of leukotrienes $\mathrm{B}_{4}$ signaling pathway induced apoptosis and suppresses cell proliferation in colon cancer. J Pharmacol Sci 2007;103:24-32.

[20] Sanchez T, Moreno JJ. Calcium-independent phospholipase $\mathrm{A}_{2}$ through arachidonic acid mobilization is involved in Caco-2 cell growth. J Cell Physiol 2002;193:293-298.

[21] Martín- Venegas R, Roig-Pérez S, Ferrer R, Moreno JJ. Arachidonic acid cascade and epithelial barrier function Turing Caco-2 cell differentiation. J Lipid Res 2006;47:1416-1423.

[22] Pai R, Soreghan B, Szabo IL, Pavelka M, Baatar D, Tarnawski AS. Prostaglandin $\mathrm{E}_{2}$ transactivates EGF receptor: a novel mechanism for promoting colon cancer growth and gastrointestinal hypertrophy. Nature Med 2002;8:289-293

[23] Dvory-Sobol H, Cohen-Noyman E, Kazanov D, Figer A, Birkenfeld S, MadarShapiro $\mathrm{L}$ et al. Celecoxib leads to $\mathrm{G}_{2} / \mathrm{M}$ arrest by induction of $\mathrm{p} 21$ and down-regulation of cyclin B1 expression in a p53-independent manner. Eur J Cancer 2006;42:422-426.

[24] Dembinski A, Konturek SJ. Effects of E, F, and I series prostaglandins and analogues on growth of gastroduodenal mucosa and pancreas. Am J Physiol 1985;248:6170-6175.

[25] Elenbaas B, Weinberg RA. Heterotypic signaling between epithelial tumor cells and fibroblasts in carcinoma formation. Exp Cell Res 2001;204:169-184. 
[26] Lloret S, Torrent M, Moreno JJ. Proliferation-dependent changes in arachidonic acid mobilization from phospholipids of 3T6 fibroblasts. Pflugers Archv. Eur J Physiol $1996 ; 432: 655-662$

[27] Nieves D, Moreno JJ. Hydroxyeicosatetraenoic acids released through the cytochrome P-450 pathway regulate 3 T6 fibroblast growth. J Lipid Res 2006;47:26812689

[28] Shao J, Sheng GG, Mifflin RC, Powell DW, Sheng H. Roles of myofibroblasts in prostaglandin $\mathrm{E}_{2}$-stimulated intestinal epithelial proliferation and angiogenesis. Cancer Res 2006;66:846-855.

[29] Vivancos M, Moreno JJ. Role of $\mathrm{Ca}^{2+}$-independent phospholipase $\mathrm{A}_{2}$ and cyclooxygenase pathways in the nitric oxide production by murine macrophages stimulated by lipopolysaccharides. Nitric Oxide Biol Chem 2002;6:255-262 [30] Pull SL, Doherty JM, Mills JC, Gordon JI, Stappenbeck TS. Activated macrophages are an adaptive element of the colonic epithelial progenitor niche necessary for regenerative responses to injury. Procc Natl Acad Sci USA 2005;102:99104.

[31] Stenson WF. Prostaglandins and epithelial response to injury. Curr Opinion Gastroenterol 2007;23:107-110.

[32] Brown SL, Riehl TE, Walker MR, Geske MJ, Doherty JM, Stenson WF, Stappenbeck TS. Myd88-dependent positionary of Ptgs2-expresiong stromal cells maintains colonic epithelial proliferation during injury, J Clin Invest 2007;117:258-269. [33] Houchen CW, Stenson WF, Cohn SM. Disruption of cyclooxygenase-1 gene results in an impaired response to radiation injury. Am J Physiol Gastrointestinal and Liver Physiol 2000;279:G858-G865. 
[34] Cohn SM, Schloemann S, Tessner T, Seibert K, Stenson WF. Crypt stem cell survival in the mouse intestinal epithelium is regulated by prostaglandins synthesized through cyclooxygenase-1. J Clin Invest 1997;99:1367-1379.

[35] Nielsen CK, Campbell JIA, Ohd JF, Morgelin M, Riesbeck KR, Landberg G, Sjolander A. A novel localization of the G-protein-coupled cysLT1 receptor in the nucleus of colorectal adenocarcinoma cells. Cancer Res 2005;65:732-742.

[36] Moreno JJ. New aspects of the role of hydroxyeicosatetraenoic acids in cell growth and cancer development. Biochem Pharmacol 2009;77:1-10.

[37] Nixon JB, Kim KS, Lamb PW, Jr Bottone FG, Eling TE. 15-lipoxygenase-1 has anti-tumorigenic effects in colorectal cancer. Prostaglandins Leukotrienes Essential Fatty Acids 2004;70:7-15.

[38] Pollard M, Luckert PH. Effect of indomethacin on intestinal tumors induced in rats by the acetate derivative of dimethylnitrosamine. Science 1981;214:558-559.

[39] Thun MJ, Namboodiri MM, Calle EE, Flanders WD, Jr. Heath CW. Aspirin use and reduced risk of fatal colon cancer. New Engl J Med 1991;325:1593-1596.

[40] Koehne CH, Dubois RN. COX-2 inhibition and colorectal cancer. Seminary Oncol 2004;31:12-21.

[41] Eberhart CE, Coffey RJ, Radhika A, Giardiello FM, Ferrenbach S, Dubois RN. Upregulation of cyclooxygenase 2 gene expression in human colorectal adenomas and adenocarcinomas. Gastroenterology 1994;107:1183-1188.

[42] Pugh S, Thomas GA. Patients with adenomatous polyps and carcinomas have increased colonic mucosal prostaglandin $\mathrm{E}_{2}$. Gut 1994;35:675-678.

[43] Moran AE, Hunt DH, Javid SH, Redston M, Carothers AM, Bertagnolli MM. Apc deficiency is associated with increased Egfr activity in the intestinal enterocytes and adenomas of C57BL/6J-Min/+ mice. J Biol Chem 2004;279:43261-43272. 
[44] Oshima M, Dinchuk JE, Kargman SL, Oshima H, Hancock B, Kwong E, et al. Suppression of intestinal polyposis in Apc delta716 knockout mice by inhibition of cyclooxygenase 2 (COX-2). Cell 1996;87:803-809.

[45] Kinzler KW, Vogelstein B. Landscaping the cancer terrain. Science 1998;280:1036-1037.

[46] Petrik MB, McEntee MF, Chiu CH, Whelan J. Highly unsaturated (n-3) fatty acids, but not alpha-linolenic, conjugated linoleic or gamma-linolenic acids, reduce tumorigenesis in Apc (Min/+) mice. J Nutr 2000;130:1153-1158.

[47] Hong KH, Bonventre JC, O’ Leary E, Bonventre JV, Lander ES. Deletion of cytosolic phospholipase $\mathrm{A}_{2}$ suppresses $\mathrm{Apc}^{\mathrm{Min}}$-induced tumorigenesis. Procc Natl Acad Sci USA 2001;98:3935-3939.

[48] Ilsley JNM, Nakanishi M, Flynn C, Belinsky GS, De Guise S, Adib JN, Dobrowsky RT, Bonventre JV, Rosenberg DW. Cytoplasmic phospholipase $\mathrm{A}_{2}$ deletion enhances colon tumorigenesis. Cancer Res 2005;65:2636-2643.

[49] Castellone MD, Teramoto H, Williams BO, Druey KM, Gutkind JS. Prostaglandin $\mathrm{E}_{2}$ promotes colon cancer cell growth through a Gs-axin-beta-catenin signaling axis. Science 2005;310:504-1510.

[50] Watanabe K, Kawamori T, Nakatsugi S, Ohta T, Ohuchida S, Yamamoto H, et al. Role of the prostaglandin $\mathrm{E}$ receptor subtype $\mathrm{EP}_{1}$ in colon carcinogensis. Cancer Res 1999;59:5093-5096.

[51] Kliewer SA, Lehmann JM, Milburn MV, Willson TM. The PPARs and PXPs: nuclear xenobiotic receptor that define moved hormone signaling pathways. Recent Progress Hormonal Res 1999;54:345-367. 
[52] Wang D, Wang H, Shi Q, Katturi S, Walhi W, Desvergue B, et al. Prostaglandin $\mathrm{E}_{2}$ promotes colorectal adenoma growth via transactivation of the nuclear peroxisome proliferators-activated receptor $\delta$. Cancer Cell 2004;6:285-295.

[53] Cianchi F, Cortesini C, Magnelli L, Fanti E, Papucci L, Schiavone N et al. Inhibition of 5-lipoxygenase by MK886 augments the antitumor activity of celecoxib in human colon cancer cells. Mol Cancer Ther 2006;5:2716-2726.

[54] Heerdt BG, Houston MA, Augenlicht LH. Potentiation by specific short-chain fatty acids of differentiation and apoptosis in human colonic carcinoma cell lines. Cancer Res 1994;54:3288-3294.

[55] Crew TE, Elder DJE, Paraskeva C. A cyclooxygenase-2 (COX-2) selective nonsteroidal anti-inflammatory drugs enhances the growth inhibitory effects of butyrate in colorectal carcinoma cells expressing COX-2 protein: regulation of $\mathrm{COX}-2$ by butyrate. Carcinogenesis 2000:21:69-77.

[56] Blumberg RS, Saubermann LJ, Strober W. Animal models of mucosal inflammation and their relation to human inflammatory bowel disease. Curr Opinion Immunol 1999;11:648-656.

[57] Medding JB, Sutherland LR, May GR. Intestinal permeability in patients with Crohn's disease. Gut 1994;35:1675-1676.

[58] Andus T, Gross V, Casar I, Krumm D, Hosp J, David M, Schölmerich J. Activation of moncytes during inflammatory bowel diease. Pathobiology 1991;59:166170.

[59] Lu J, Philpott DJ, Saunders PR, Perdue MH, Yang PC, McKay DM. Epithelial ion transport and barrier abnormalities evoked by superantigen-activated immune cells are inhibited by interleukin-10 bot not interleukin-4. J Pharmacol Exp Ther 1998;287:128136. 
[60] Turner JR. Molecular basis of epithelial barrier regulation: from basic mechanisms to clinical application. Am J Pathol 2006;169:1901-1909.

[61] Lauritsen K, Laursen LS, Bukhave K, Rask-Madsen J. In vivo profiles of eicosanoids in ulcerative colitis, Crohn's colitis, and Clostridium difficile colitis. Gastroenterology 1988;95:11-17.

[62] Wardle TD, Hall L, Turnberg LA. Use of coculture of colonic mucosal biopsies to investigate the release of eicosanoids by inflamed and uninflamed mucosa from patients with inflammatory bowel disease. Gut 1992;33:1644-1651.

[63] Carty E, De Brabander M, Feakins RM, Rampton DS. Measurement of in vivo rectal mucosal cytokine and eicosanoids production in ulcerative colitis using filter paper. Gut 2000;46:487-492.

[64] Subbaramaiah K, Yoshimatsu K, Scherl E, Das KM, Glazier KD, Golijanin D, et al. Microsomal prostaglandin E synthase-1 is overexpressed in inflammatory bowel disease. J Biol Chem 2004;279:12647-12658.

[65] Fretland DJ, Djuric SW, Gaginella TS. Eicosanoids and inflammatory bowel disease: regulation and prospects for therapy. Prostaglandins Leukotrienes and Essential Fatty Acids 1990;41:215-233.

[66] Schreiber S, Raedler A, Stenson WF, MacDermott RP. The role of the mucosal immune system in inflammatory bowel disease. Gastroenterol Clin North Am 1992;21:451-501.

[67] Resta-Lenert S, Barrett KE. Enteroinvasive Bacteria alter barrier and transport properties of human intestinal epithelium: role of iNOS and COX-2. Gastroenterology 2002;122:1070-1087.

[68] Artis D. Epithelial-cell recognition of commensal bacteria and maintenance of immune homeostasis in the gut. Nature Rev Immunol 2008;8:411-420. 
[69] Kinoshita M, Suzuki Y, Saito Y. Butyrate reduces colonic paracellular permeability by enhancing PPARgamma activation. Biochem Biophys Res Commun 2002;293:827-831.

[70] Rodríguez-Lagunas MJ, Martín-Venegas R, Moreno JJ, Ferrer R. PGE 2 receptors involved in the regulation of epithelial barrier function in Caco-2 cell monolayers. J Physiol Biochem 2007;63:631.

[71] Bjarnasson I, Hayllar J, MacPherson AJ, Russell AS. Side effects of nonsteroidal anti-inflammatory drugs on the small and large intestine in humans. Gastroenterology 1993;104:1832-1847.

[72] Rodríguez-Lagunas MJ, Martín-Venegas R, Moreno JJ, Ferrer R. Role of N-6 PUFA derived lípido mediator son epithelial barrier function in intestinal Caco- 2 cell monolayers. $3^{\text {rd }}$ International Immunonutrition Workshop.

[73] Van der Pouw Kraan TC, Boeije LC, Smeenk RJ, Wijdenes J, Aarden LA. Prostaglandin $\mathrm{E}_{2}$ is a potente inhibitor of human interleukin 12 production. J Exp Med $1995 ; 181: 775-779$.

[74] Wu CY, Wang K, McDyer JF, Seder RA. Prostaglandin $E_{2}$ and dexamethasone inhibit IL-12 receptor expression and IL-12 responsiveness. J Immunol 1998;161:27232730.

[75] Morham SG, Langenbach R, Loftin CD, Tiano HF, Vouloumanos N, Jennette JC et al. Prostaglandin synthase 2 gene disruption causes severe renal pathology in the mouse. Cell 1995;83:473-482.

[76] Newberry RD, Stenson WF, Lorenz RG. Cyclooxygenase-2-dependent arachidonic acid metabolites are essential modulators of the intestinal immune response to dietary antigen. Nature Med 1999;5:900-906 
[77] Mutoh M, Watanabe K, Kitamura T. Involvement of prostaglandin E receptor

1

EP(4) in colon carcinogenesis. Cancer Res 2002;62;28-32.

[78] Kabashima K, Saji T, Murata T, Nagamachi M. The prostaglandin receptor EP4 suppresses colitis, mucosal damage and CD4 cell activation in the gut. J Clin Invest 2002;109:883-893 
Figure 1. Scheme of the main enzymes and metabolites of the arachidonic acid cascade.

Figure 2. Structure of the small and large intestine considering epithelial cell proliferation and differentiation along the crypt-villus axis. The asymmetric processes of eicosanoid formation and degradation might lead to an eicosanoid gradient along the cryp-villus (represented by dotted appearance). The elevated eicosanoid concentration in the neighborhood of crypt bottom is involved in the regulation of stem cell proliferation and consequently on cell migration toward the tip villus where the most differentiated epithelial cells were localized. Moreover, in this villus zone the epithelium shows the highest barrier function. The injury of the epithelium induces PSC migration to the crypt bottom, the enhancement of eicosanoid synthesis and consequently the proliferation of stem cells to renew the epithelium. Other conditions in which eicosanoid gradient is modified are IBD characterized by the disruption of epithelial barrier function. Furthermore, the chronicity of these events increases the risk of colorectal cancer development.

Figure 3. Effects of eicosanoid balance on immunoregulation, proliferation/differentiation and paracellular permeability. In physiological conditions (upper figure), the balance of eicosanoid levels participate in the control of the above mentioned events, resulting in the maintenance of epithelial homeostasis. The treatment with NSAIDs, may disrupt this balance, reducing PGs levels and thus increasing the production of LTs/HETEs. Consequently, these effects may induce the up-regulation of the immune response and the disruption of epithelial barrier function, that may be involved in the development and exacerbation of IBD. 

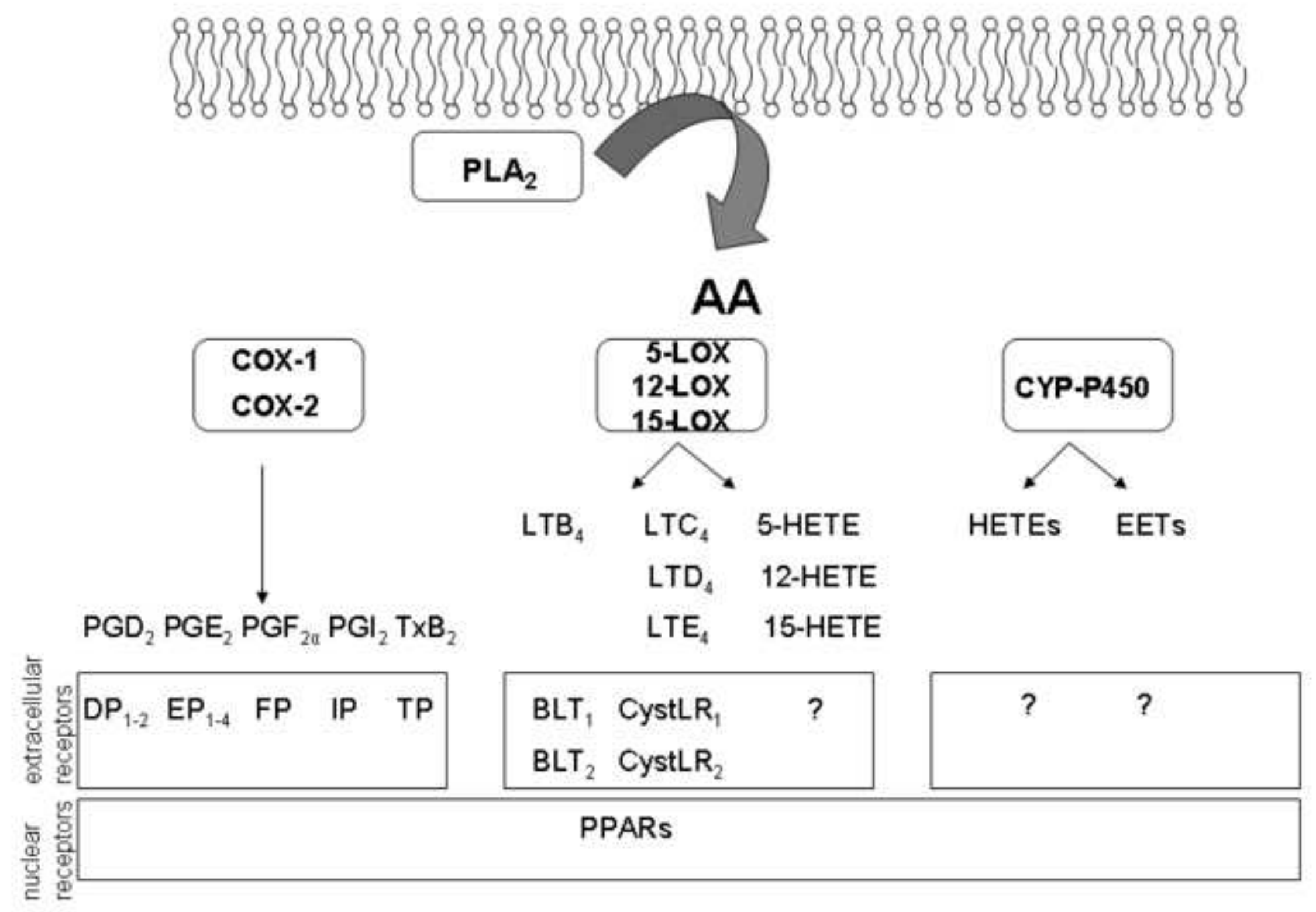


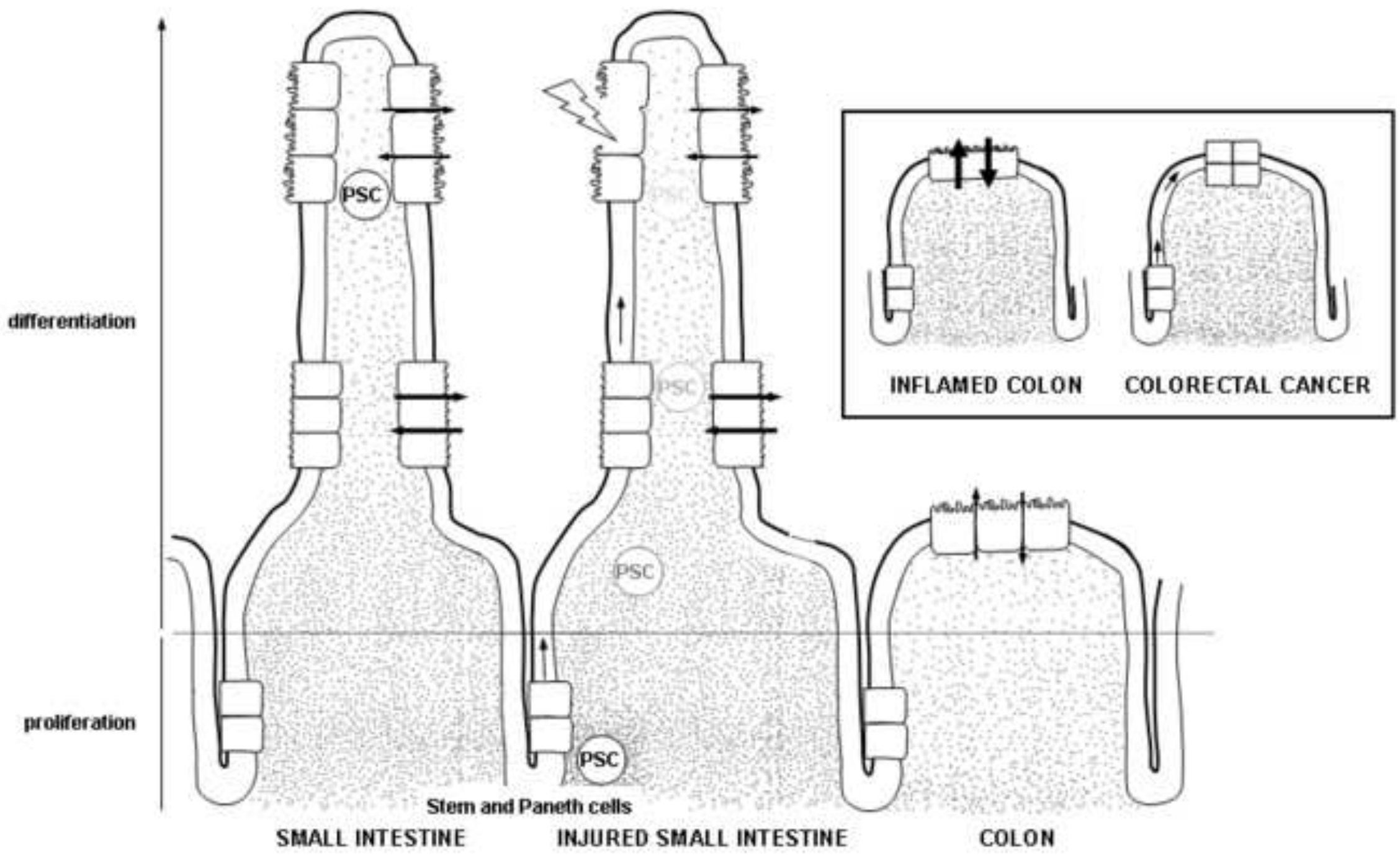




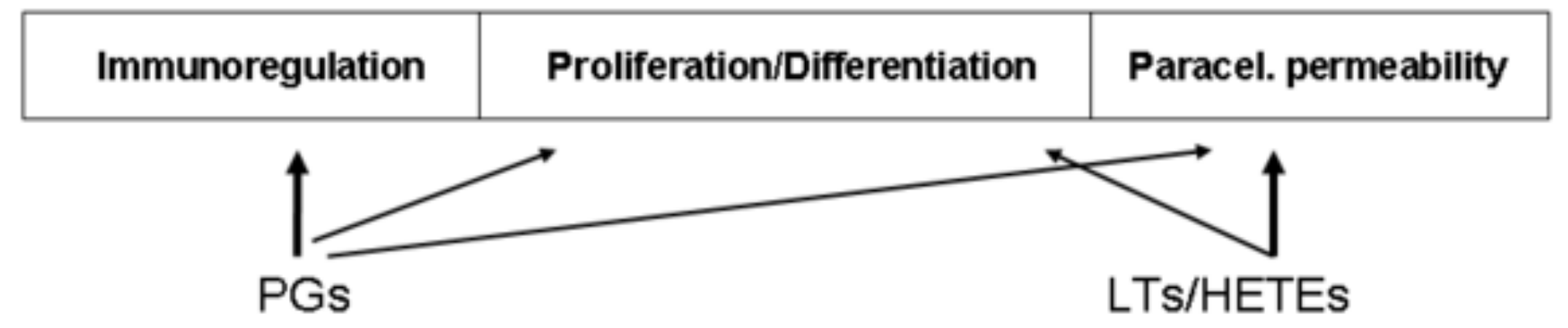

+ NSAIDs
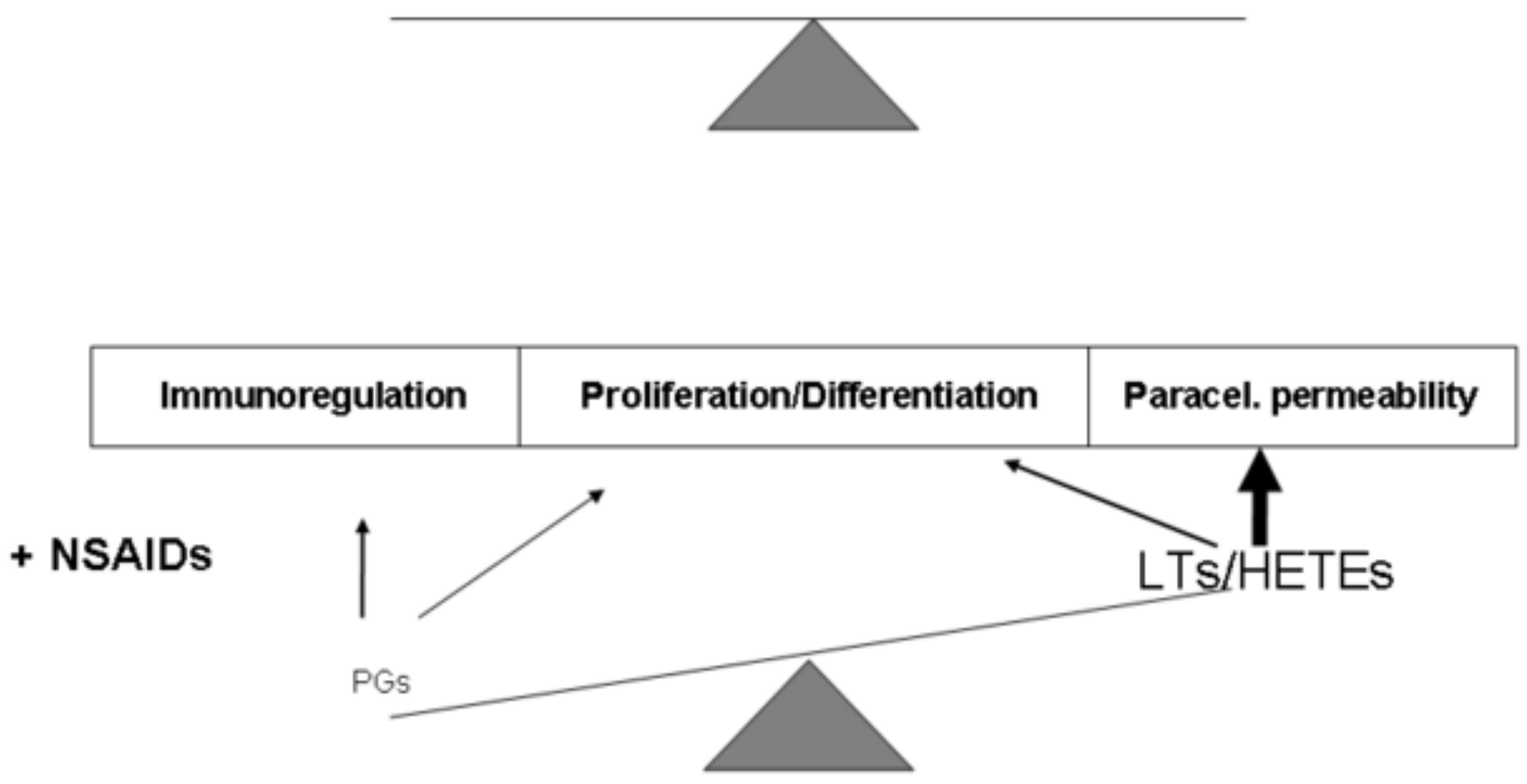


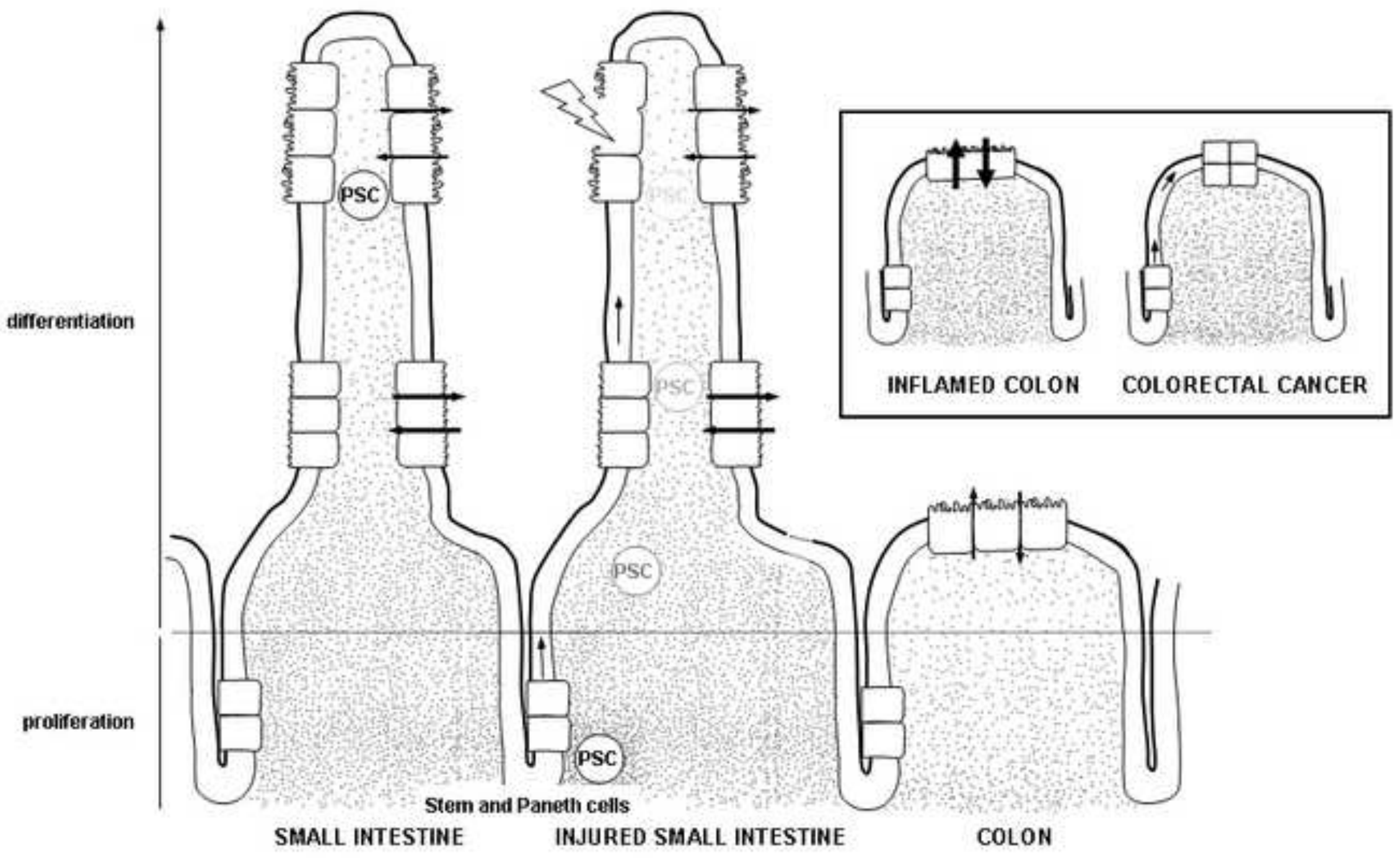

